\title{
Premenstrual asthma: still poorly understood
}

\author{
Brian J O’Connor
}

Although a premenstrual increase in symptoms can occur in up to $40 \%$ of women with asthma, the mechanisms underlying this phenomenon are poorly understood and have not been frequently evaluated. ${ }^{12}$ This deterioration may represent an exaggeration of the normal cyclical variation in airway function in patients with asthma since a fall in peak respiratory flow rates occurs even in those patients without significant change in premenstrual symptoms. ${ }^{3}$ Premenstrual worsening of lung function begins 7-10 days before the onset of menses and peaks 2-3 days before their onset. This change in asthma in the latter half of the luteal phase of the menstrual cycle would appear, on the face of it, to be related to changes in female hormone activity. In particular, the observed improvement in severe premenstrual asthma seen with intramuscular progesterone would imply an abnormal level of this hormone during the late luteal phase of menstruation in this group of patients. ${ }^{4}$

Although the underlying mechanisms are unclear, it seems logical to expect that patients with premenstrual exacerbations of asthma would exhibit increased airway responsiveness and evidence of airway inflammation. Surprisingly, the study by Tan et al reported in this issue of Thorax is the first to establish clearly an increase in airway responsiveness during the luteal phase of the menstrual cycle. ${ }^{5}$ In a group of 15 stable asthmatic women without premenstrual symptoms, 10 of whom were taking inhaled corticosteroids, a 2.5 fold increase in airway responsiveness to adenosine 5'-monophosphate (AMP), an indirect bronchoconstrictor acting predominantly through mast cells, ${ }^{6}$ was seen. These data contrast with two other studies in similar groups of mild asthmatic patients, neither of which demonstrated changes in airway responsiveness to methacholine or histamine, direct smooth muscle stimuli. ${ }^{78}$

This new finding using the indirect stimulus AMP requires explanation. The authors postulate that the increased response to AMP may be due to regulation of adenosine receptors on airway mast cells under the influence of circulating sex hormones. However, they failed to find a correlation between circulating hormone levels and changes in $\mathrm{PC}_{20} \mathrm{AMP}$ which makes this unlikely. On a simple level it seems plausible to believe that, during the menstrual cycle, there are changes in asthmatic inflammation within female airways. AMP challenge may be a more discriminatory tool than the smooth muscle stimuli methacholine or histamine as adenosine acts indirectly on both airway mast cells and airway sensory nerves. ${ }^{6}$ The observations of Tan and colleagues may therefore reflect upregulation of either or both processes as a measure of increased inflammation. Against this, serum levels of eosinophil cationic protein (ECP), a surrogate marker of airway inflammation, albeit poor, was unchanged between the follicular and luteal phases. This study prompts further research in menstruating females using other established markers of airway inflammation.

There are now several non-invasive tools to evaluate airway inflammation in asthma that may be applicable in premenstrual asthma. Nitric oxide (NO), a gas present in exhaled air, is increased in patients with asthma. ${ }^{9}$ Exhaled $\mathrm{NO}$ is thought to be a marker of airway inflammation as the abnormal levels recorded in patients with symptomatic asthma are reduced by inhaled corticosteroid treatment. ${ }^{10}$
Furthermore, the acute rise in NO levels observed during the late asthmatic response following allergen challenge correlates with the severity of bronchoconstriction. ${ }^{11} \mathrm{~A}$ recent study in normal women which clearly showed higher levels of exhaled NO during the luteal phase of the menstrual cycle may provide a clue to possible airway inflammatory changes in premenstrual asthma. ${ }^{12}$ This study needs to be repeated in women with asthma, ideally in those with objective evidence of premenstrual worsening of asthma control. The techniques used to process and analyse sputum samples obtained by induction with hypertonic saline have been refined to show changes in airway inflammation clearly, particularly eosinophil function measured by absolute counts and sputum levels of ECP. ${ }^{13}$ In combination with measurement of exhaled NO, assessment of sputum eosinophil activity could be readily and safely performed throughout both phases of the menstrual cycle of asthmatic patients.

Tan et al also reported a loss of normal cyclical changes in $\beta_{2}$ adrenoceptor regulation previously described in normal women by the same group. ${ }^{14}$ This occurred despite an appropriate rise in luteal phase sex hormones in the asthmatic patients studied. In a previous study from the same group exogenous progesterone upregulated follicular phase $\beta_{2}$ adrenoceptor function in normal women. ${ }^{15}$ Thus, as the authors suggest, the present findings may indicate a poor $\beta_{2}$ adrenoceptor response to increased luteal phase endogenous progesterone in asthmatic patients. Since female sex steroid hormones potentiate the bronchorelaxant effects of catecholamines, ${ }^{16}$ this blunted $\beta_{2}$ adrenoceptor response may contribute to the mechanisms underlying premenstrual asthma. It is not possible to draw any firm conclusions from this study as the patients assessed did not have overt premenstrual asthma. The lack of data on patients with objective premenstrual loss of asthma control hampers the development of insights into this problem.

Although as many as $40 \%$ of patients have premenstrual asthma, ${ }^{1}$ most are likely to be controlled with standard treatment guidelines including increasing inhaled corticosteroids and possibly adding long acting $\beta_{2}$ adrenoceptor agonists during the second half of the menstrual cycle. Studies are needed to establish clear treatment protocols. As Tan et al suggest, these studies should include evaluation of theophylline, an adenosine antagonist, ${ }^{17}$ and the cromones which effectively attenuate adenosine-induced bronchoconstriction ${ }^{18}$ in view of the significant increase in AMP responsiveness during the luteal phase. Of particular note, the patients most prone to premenstrual exacerbations are those with severe asthma. ${ }^{4}$ In many cases even high dose oral steroids are of little benefit. In these difficult patients intramuscular progesterone has been advocated as an alternative treatment. ${ }^{4}$ Overall, there is a paucity of data on underlying mechanisms and possible treatment regimens for premenstrual asthma. It behoves respiratory physicians to develop a programme of research in this poorly understood subgroup of asthmatic patients.

Senior Lecturer and Consultant Chest Physician, King's College Hospital,

Denmark Hill,

London SE5, UK 
1 Gibbs CJ, Coutts II, Lock R, Finnegan OC, White RJ. Premenstrual exacerbation of asthma. Thorax 1984;39:833-6.

2 Hanley SP. Asthma variation with menstruation. Br f Dis Chest 1981;75: 306-8.

3 Pauli BD, Reid RL, Munt PW, Wigle RD, Forkert L. Influence of the menstrual cycle on airway function in asthmatic and normal subjects. Am Rev Respir Dis 1989;140:358-62.

4 Beynon HL, Garbett ND, Barnes PJ. Severe premenstrual exacerbations of asthma: effect of intramuscular progesterone. Lancet 1988;ii:370-2.

5 Tan KS, McFarlane LC, Lipworth BJ. Loss of normal cyclical $\beta_{2}$ adrenoceptor regulation and increased premenstrual responsiveness to adenosine monophosphate in stable female asthmatic patients. Thorax 1997;52: 608-11.

6 Polosa R, Phillips GD, Rafakulasingam K, Holgate ST. The effect of inhaled ipratropium bromide alone and in combination with oral terfenadine on bronchoconstriction provoked by adenosine $5^{\prime}$-monophosphate and histamine in asthma. F Allergy Clin Immunol 1991;87:939-47.

7 Juniper EF, Kline PA, Roberts RS, Hargreave FE, Daniel EE. Airway responsiveness to methacholine during the natural menstrual cycle and responsiveness to methacholine during the natural menstrual cycle and

8 Weinmann GG, Zacur H, Fish JE. Absence of changes in airway responsiveness during the menstrual cycle. F Allergy Clin Immunol 1987;79: 634-8

9 Kharitonov SA, Yates D, Robbins RA, Logan-Sinclair R, Shinebourne EA, Barnes PJ. Increased nitric oxide in exhaled air of asthmatic patients. Lancet 1994;343:133-5.
10 Kharitonov SA, Yates DH, Barnes PJ. Inhaled glucocorticoids decrease nitric oxide in exhaled air of asthmatic patients. Am $\mathcal{F}$ Respir Crit Car Med 1996;153:454-7.

11 Kharitonov SA, O'Connor BJ, Evans DJ, Barnes PJ. Allergen-induced late asthmatic reactions are associated with elevation of exhaled nitric oxide. Am $\mathcal{F}$ Respir Crit Care Med 1995;151:1894-9.

12 Kharitonov SA, Logan-Sinclair RB, Busset CM, Shinebourne EA. Peak expiratory nitric oxide differences in men and women: relation to the menstrual cycle. Br Heart $\mathcal{f} 1994 ; 72: 243-5$.

13 Pizzichini MM, Popov TA, Efthimiadis A, Hussack P, Evans S, Pizzichin $\mathrm{E}$, et al. Spontaneous and induced sputum to measure indices of airwa inflammation in asthma. Am $\mathcal{F}$ Respir Crit Care Med 1996;154:866-9.

14 Wheeldon NM, Newnham DM, Coutie WJ, Peters JA, McDevitt DG Lipworth BJ. Influence of sex-steroid hormones in the regulation of lymphocyte beta 2 -adrenoceptors during the menstrual cycle. $\mathrm{Br} F$ Clin Pharmacol 1994;37:583-8.

15 Tan KS, McFarlane LC, Coutie WJ, Lipworth BJ. Effects of exogenous female sex-steroid hormones on lymphocyte beta 2 -adrenoceptors in normal females. Br $\mathcal{F}$ Clin Pharmacol 1996;41:414-6.

16 Foster PS, Goldie RG, Paterson JW. Effect of steroids on beta-adrenoceptormediated relaxation of pig bronchus. Br F Pharmacol 1983;78:441-5.

17 Clarke H, Cushley MJ, Persson CG, Holgate ST. The protective effects of intravenous theophylline and enprofylline against histamine- and adenosine 5'-monophosphate-provoked bronchoconstriction: implications for the mechanisms of action of xanthine derivatives in asthma. Pulmon Pharmacol 1989;2:147-54

18 Church MK, Holgate ST. Adenosine-induced bronchoconstriction and its inhibition by nedocromil sodium. Allergy Clin Immunol 1993;92:190-4. 